\title{
Adenosine-Containing Neurons in the Brain Localized by Immunocytochemistry
}

\author{
Karen M. Braas, Andrew C. Newby, ${ }^{*}$ Virginia S. Wilson, and Solomon H. Snyder \\ Departments of Neuroscience, Pharmacology and Experimental Therapeutics, Psychiatry and Behavioral Sciences, \\ The Johns Hopkins University School of Medicine, Baltimore, Maryland 21205, and *Department of Cardiology, \\ Weish National School of Medicine, Heath Park, Cardiff CF4 4XN, Wales
}

Specific sensitive rabbit antisera directed against the adenosine derivative laevulinic acid $\left(O^{2}, 3^{\prime}\right.$-adenosine acetal), which are capable of detecting as little as 1 pmol of adenosine by radioimmunoassay and which require more than 1000 - to 40,000 -fold greater concentrations of adenine nucleotides to displace adenosine binding to antisera, have been developed. These antisera were employed to localize adenosine immunoreactivity throughout the rat CNS using the peroxidase-antiperoxidase (PAP) complex and avidin-biotin-peroxidase complex (ABC) immunocytochemical techniques. Intense staining for adenosine immunoreactivity was localized to the cytoplasm of perikarya and fibers in neuronal cell groups of discrete rat brain regions. Areas containing highest levels of immunoreactivity included the pyramidal cells of the hippocampus, the granule cells of the dentate gyrus, subnuclei of the thalamus, amygdala, and hypothalamus, the primary olfactory cortex, and many motor and sensory nuclei of the brain stem and spinal cord. High levels also occurred in certain layers of the cerebral cortex, the caudate-putamen, the septal nuclei, and the Purkinje cell layer of the cerebellum. Varying the extent of tissue hypoxia altered only the levels of endogenous immunoreactive adenosine without changing the pattern of distribution of the immunoreactivity. Staining was abolished by immunoabsorption and by pretreatment of tissue sections with adenosine deaminase. The localization of adenosine to discrete neuronal groups in the brain supports the possibility of a neurotransmitter or neuromodulatory role for adenosine.

The numerous influences of the purine nucleoside adenosine on interneuronal communication within the CNS suggest a role as a neurotransmitter or neuromodulator. Adenosine exerts its effects via 2 distinct receptor subtypes coupled to adenylate cyclase: a high-affinity inhibitory $A_{1}$ receptor and a low-affinity stimulatory $A_{2}$ receptor (Cooper et al., 1980; Van Calker et al., 1979). Binding sites associated with adenosine $A_{1}$ receptors have been localized in the brain using in vitro autoradiographic techniques with ${ }^{3} \mathrm{H}$-cyclohexyladenosine (Goodman and Snyder, 1981, 1982; Lewis et al., 1981). Lesion studies suggest that these sites are associated with axon terminals of excitatory neu-

Received Aug. 5, 1985; revised Dec. 16, 1985; accepted Dec. 30, 1985

This work was supported by United States Public Health Service Grants MH18501, DA-00266, NS-16375, Research Scientist Award DA-00074 to S.H.S., and a grant from the International Life Sciences Institute. K.M.B. is a recipient of United States Public Health Service Fellowship NS-07073. We are grateful to Dawn C. Dodson and Nancy Bruce for their efforts in the preparation of this manuscript. We also thank Victor May for his scientific support and his input into the writing of this manuscript.

Correspondence should be addressed to Solomon H. Snyder, Department of Neuroscience, The Johns Hopkins University School of Medicine, 725 North Wolfe Street, Baltimore, MD 21205.

Copyright (C) 1986 Society for Neuroscience $0270-6474 / 86 / 071952-10 \$ 02.00 / 0$ ronal pathways (Goodman et al., 1983), which is consistent with inhibitory neurophysiological actions of adenosine that appear to involve blockade of excitatory neurotransmitter release (Fredholm and Hedqvist, 1980; Harms et al., 1979; Kocsis et al., 1984; Kostopoulos and Phillis, 1977; Kostopoulos et al., 1975; Phillis and Wu, 1981; Phillis et al., 1979).

The correlation of behavioral potencies of xanthines with an affinity for adenosine receptors, and the potent sedating effects of lipophilic adenosine derivatives suggest that the behavioral effects of xanthines arise from blockade of adenosine receptors (Barraco et al., 1983; Katims et al., 1983; Snyder et al., 1981).

Similar to classical neurotransmitters, adenosine is released from nerve terminals following depolarization, although the calcium dependence of this process is unclear (Bender et al., 1981; Dunwiddie and Fredholm, 1984; Pull and McIlwain, 1977; Stone, 1981). In addition, there exists an energy-dependent, high-affinity uptake system for adenosine, which could provide a mechanism for removal of synaptically released adenosine (Bender et al., 1980; Kuroda and Mcllwain, 1974; Shimizu et al., 1972). Autoradiographic studies utilizing the potent adenosine uptake inhibitor ${ }^{3} \mathrm{H}$-nitrobenzylthioinosine (Jarvis and Young, 1980; Marangos et al., 1982) have demonstrated discrete regional localization of adenosine uptake sites (Bisserbe et al., 1985; Nagy et al., 1985). Whether adenosine uptake occurs specifically into adenosine-containing neurons remains to be established. Adenosine deaminase, which is involved in the conversion of adenosine to inosine, has also been localized immunocytochemically to discrete brain regions (Nagy et al., 1984a, 1985).

Despite all the evidence suggesting a role for adenosine in the brain, it is not clear whether adenosine in the brain occurs specifically in neurons or other cell types. Previously, histochemical methods have not been available to identify adenosine in the CNS. We have utilized sensitive and specific antisera to localize adenosine to specific neuronal cell groups throughout the rat CNS using immunocytochemical techniques. Preliminary results have been described earlier (Braas et al., 1985).

\section{Materials and Methods}

\section{Tissue preparation}

Adult male Sprague-Dawley rats (150-250 gm) given ad libitum access to commercial rat chow and tapwater were maintained on a $12 \mathrm{hr}$ light/ $12 \mathrm{hr}$ dark cycle. For routine immunocytochemical studies, animals under sodium pentobarbital anesthesia were sequentially perfused intracardially with balanced salt solution, buffered fixative, and 7\% sucrose in $0.15 \mathrm{~m}$ sodium phosphate buffer, $\mathrm{pH} 7.4$. Fixatives included $4 \%$ paraformaldehyde, $2 \%$ paraformaldehyde, 4 or $2 \%$ paraformaldehyde containing $0.1,0.2$, or $0.5 \%$ glutaraldehyde, picric acid formaldehyde, $1 \%$ glutaraldehyde, $2.5 \%$ glutaraldehyde, periodate lysine paraformaldehyde (McLean and Nakane, 1974), and periodate lysine paraformaldehyde glutaraldehyde (Gendelman et al., 1983). Fixatives were pre- 
parcd in $0.15 \mathrm{M}$ sodium phosphate buffer, $\mathrm{pH}$ 7.4. In initial experiments, $2.5 \%$ glutaraldehyde provided the best preservation of antigenicity and tissue structure; accordingly, this fixative was used in subsequent studies. Following perfusion, the brains were rapidly removed and cut into 2$3 \mathrm{~mm}$ coronal slices using a Jacobowitz rat brain slicer (Jacobowitz, 1974), and placed in fresh buffered sucrose. Tissue slices were embedded either in brain paste and rapidly frozen for cryostat sectioning, or in $2 \%$ agar for vibratome sectioning.

Since cellular levels of ATP and adenosine vary greatly depending upon the physiological state of the animal, brain tissue was prepared by 3 methods to determine their effects on the immunocytochemical stain. In one group of animals, the duration of the initial intracardial perfusion wash was varied $(0.0,0.5,1.0$, and $5.0 \mathrm{~min})$ prior to fixation with $2.5 \%$ glutaraldehyde. The second group of rats was killed by decapitation. Brains were cut into 1-2 mm coronal sections, fixed with buffered $2.5 \%$ glutaraldehyde, washed in buffered sucrose, and processed for cryostat sectioning. The third group of rats was killed by focused microwave irradiation $(2.5-4.5 \mathrm{sec}, 3.5 \mathrm{~kW}, 2.45 \mathrm{GHz}$; Litton Menumaster 70/50) and the brains processed for immunocytochemical staining.

\section{Immunocytochemical stain}

Vibratome $(30 \mu \mathrm{m})$ or cryostat $(8 \mu \mathrm{m})$ tissue sections were stained using a modification of the peroxidase-antiperoxidase (PAP) complex technique (Braas et al., 1983; Moriarty and Halmi, 1972; Sternberger et al., 1970 ) or the avidin-biotin-peroxidase complex (ABC) technique (Childs and Unabia, 1982; Hsu et al., 1981). The procedures for adenosine haptenization and the production and characterization of specific antisera have been described previously (Newby and Sala, 1982). Rabbits were immunized with laevulinic acid $\left(O^{2 \prime} 3^{3}\right.$-adenosine-acetal) synthesized by the method of Seela and Cramer (1975), which was coupled to human serum albumin. The antisera from 3 animals (rabbits 1, 3, and 4), which had demonstrated binding of more than 100 pmol of adenosine/ $\mathrm{ml}$ of serum, were screened for their immunoreactivity under staining conditions. The staining procedure was as follows: (1) pretreatment of tissue-incubation with $0.2 \%$ Triton-X 100 in $0.1 \mathrm{M}$ sodium

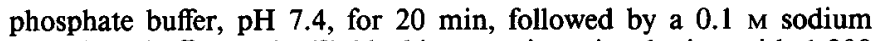
phosphate buffer wash; (2) blocking reaction-incubation with 1:200 normal goat serum (NGS) for $15 \mathrm{~min}$, then blotting off excess; (3) primary antibody reaction - incubation in 1:100-1:50,000 primary antiserum for $48 \mathrm{hr}$ at $4^{\circ} \mathrm{C}$, then washing with $0.1 \mathrm{M}$ phosphate buffer containing $0.05 \%$ Triton-X 100 ; (4) blocking reaction; (5) second antibody reaction-incubation in either 1:200 goat anti-rabbit IgG or $1: 400$ biotinylated goat anti-rabbit IgG in 1:200 NGS for $60 \mathrm{~min}$, followed by a phosphate buffer wash containing $0.05 \%$ Triton-X $100 ;(6)$ blocking reaction; (7) label complex - incubation with either 1:100 PAP complex or 1:200 ABC in 1:200 NGS for $60 \mathrm{~min}$, followed by a phosphate buffer wash; (8) peroxidase reaction-incubation with diaminobenzidine and $\mathrm{H}_{2} \mathrm{O}_{2}$ as substrates $(0.3 \mathrm{mg} / \mathrm{ml}$ diaminobenzidine and $0.03 \% \mathrm{H}_{2} \mathrm{O}_{2}$ in $0.05 \mathrm{M}$ Tris buffer, $\mathrm{pH} 7.6$ ) for 10 to $30 \mathrm{~min}$, followed by a wash with phosphate buffer; (9) osmium tetroxide reaction-exposure to osmium tetroxide vapors for 5-10 min to enhance the reaction product. All antisera were diluted in sterile $0.05 \mathrm{M}$ sodium phosphatc buffer, $\mathrm{pH} 7.4$, containing $2.5 \mathrm{mg} / \mathrm{ml}$ human serum albumin.

\section{Staining controls}

The specificity of the immunocytochemical stain was determined using immunoabsorption, enzymatic degradation of antigen, and method controls. Displacement of adenosine binding to the antisera by other compounds has been previously described (Newby and Sala, 1982). All control studies were performed on tissue from rats that were perfused for $0.5 \mathrm{~min}$ with prewash followed by buffered $2.5 \%$ glutaraldehyde.

For immunoabsorption tests, primary antiserum $(1,3)$ was absorbed with adenosine or heterologous antigen ( $1 \mathrm{ng}$ to $100 \mu \mathrm{g} / \mathrm{ml}$ of serum) at $4^{\circ} \mathrm{C}$ for $24-48 \mathrm{hr}$ prior to immunocytochemical staining of serial rat brain vibratome sections or cryosections.

Solid phase immunoabsorption was also performed. Antiserum $(1,3)$, diluted in $0.15 \mathrm{~m}$ sodium phosphate buffer, $\mathrm{pH} 7.0$, was applied to a laevulinoyladenosylsepharose ( $10.3 \mu \mathrm{mol}$ adenosine/gm wet resin; $5 \mathrm{ml}$ bed volume) column (Seela and Waldek, 1975), and eluted with 0.15 M sodium phosphate buffer, pH 7.0. Fractions of $1.0 \mathrm{ml}(0.1 \mathrm{ml} / \mathrm{min}$ flow rate) were collected and assayed for specific binding according to the method of Newby and Sala (1982). Samples of representative frac- tions were lyophilized, dissolved in staining buffer containing 1:200 NGS, and used to immunocytochemically stain serial vibratome sections.

To destroy endogenous adenosine, serial cryosections were incubated with adenosine deaminase $(0.2 \mathrm{U} / \mathrm{ml}$ to $2 \mathrm{U} / \mathrm{ml})$ for $5,15,30$, or 60 min at $37^{\circ} \mathrm{C}$ prior to immunocytochemical staining. Serial control sections received enzyme vehicle only.

Brain sections were also stained using normal rabbit (preimmune) serum to replace the primary antibodies. Additional sections were stained omitting primary antibody, goat or biotinylated goat anti-rabbit IgG, or ABC or PAP complex.

\section{Materials}

Reagents were obtained from the following sources: calf intestine adenosine deaminase, Boehringer-Mannheim (Indianapolis, IN); nucleotides, nucleosides, and their bases, Sigma (St. Louis, MO); human serum albumin, Calbiochem-Behring (La Jolla, CA). All other reagents were analytical grade. Immunochemicals were obtained from the following sources: goat anti-rabbit IgG and normal rabbit serum, Kallestad (Chaska, MN); PAP complex, N. L. Cappel Laboratories (Cochranville, PA); normal goat serum, biotinylated goat anti-rabbit $\mathrm{IgG}$, and $\mathrm{ABC}$, Vector Laboratories (Burlingame, CA).

\section{Results}

\section{Immunocytochemical stain for adenosine: general properties}

Endogenous levels of the adenine nucleotides in the brain are 100-1000-fold higher than those of adenosine (Winn et al., 1980). It was therefore necessary to develop antisera with considerable selectivity for adenosine. The antisera employed in the present study were obtained by immunization of rabbits with the adenosine derivative laevulinic acid $\left(O^{2,}, 3^{\prime}\right.$-adenosine acetal) (Seela and Cramer, 1975) coupled to human serum albumin. This haptenization of adenosine preserved both the purine and ribose rings of the native adenosinc structurc. The resultant antisera are both sensitive and selective, and are capable of detecting 1 pmol of adenosine by radioimmunoassay (Newby and Sala, 1982). Greater than 1000-40,000-fold higher concentrations of ATP, ADP, AMP, cAMP, inosine, hypoxanthine, and adenine are required to displace adenosine binding from the antisera, while 2 '-deoxyadenosine has a similar affinity to adenosine (Newby and Sala, 1982).

In initial experiments, we detected adenosine-like immunoreactivity in discrete neuronal cell groups throughout the brain. Adenosine immunoreactivity was most prominent throughout the cytoplasm of select perikarya, while staining was absent over nuclei. Staining often extended into dendritic and axonal processes of neurons. Numerous densities of fibers and axon terminals were also observed in regions of the hindbrain. Antisera $(1,3),(3,5)$, and $(4,5)$ produced similar immunocytochemical staining patterns, and serum $(1,3)$, a later bleeding of the antiserum $(1,2)$ previously described by Newby and Sala (1982), was selected for routine use. The optimal staining dilutions for antiserum $(1,3)$ were $1: 7000$ to $1: 12,000$.

To validate that the immunoreactivity observed in our studies was specific for adenosine itself, we conducted a number of control experiments (Table 1). In liquid phase immunoabsorption studies, staining was reduced to background levels when tissue sections were stained with anti-adenosine preabsorbed with adenosine. Staining remained intense, however, when the antiserum was preabsorbed with other adenine nucleotides and related compounds (Table 1). 2'-Deoxyadenosine also eliminated staining, while higher amounts of cAMP and adenine $(100$ $\mu \mathrm{g} / \mathrm{ml}$ serum) reduced staining intensity. These results paralleled those observed for the specificity of the antisera by radioimmunoassay.

Solid phase immunoabsorption of anti-adenosine was also performed. Antiserum was applied to a column containing laevulinic acid $\left(O^{2}, 3^{\prime}\right.$-adenosine acetal $)$ linked to Sepharose. Bind- 


\begin{tabular}{|c|c|}
\hline Controls & Immunoreactivity $^{a}$ \\
\hline \multicolumn{2}{|l|}{ Immunoabsorption ${ }^{b}$} \\
\hline Adenosine & - \\
\hline Laevulinic acid $\left(O^{2}, 3^{\prime} \text {-adenosine acetal }\right)^{c}$ & - \\
\hline ATP & + \\
\hline ADP & + \\
\hline AMP & + \\
\hline cAMP & \pm \\
\hline Guanosine & + \\
\hline Inosine & + \\
\hline Uridine & + \\
\hline Thymidine & + \\
\hline Hypoxanthine & + \\
\hline 2'-Deoxyadenosine & - \\
\hline Adenine & \pm \\
\hline $\begin{array}{l}\text { Adenosine deaminase pretreatment } \\
\text { of tissue secton }\end{array}$ & - \\
\hline Normal rabbit (preimmune) serum & - \\
\hline \multicolumn{2}{|l|}{ Omission of stain component } \\
\hline Anti-Adenosine & - \\
\hline Goat anti-rabbit IgG & - \\
\hline $\mathrm{ABC}$ or PAP complex & - \\
\hline
\end{tabular}

Primary antiserum was absorbed with the indicated antigens for $24-48 \mathrm{hr}$ prior to immunocytochemical staining. An aliquot of anti-adenosine was also applied onto a laevulinoyladenosylsepharose column as described and the eluted fractions screened for immunoreactivity. Adult male rats were perfused with saline for $0.5 \mathrm{~min}$, followed by $2.5 \%$ glutaraldehyde in $0.15 \mathrm{M}$ sodium phosphate buffer, $\mathrm{pH}$ 7.4. Serial coronal vibratome or cryostat tissue sections were immunocytochemically stained, as described in Materials and Methods. Additional sections were treated with adenosine deaminase prior to immunocytochemical staining or were stained with normal rabbit serum. Method controls included omission of individual components of the stain. Each control experiment was performed 2-5 times, with identical results.

${ }^{a}$ Immunoreactivity: + , unchanged; - , abolished; \pm , reduced.

${ }^{b} 1 \mathrm{ng}-100 \mu \mathrm{g}$ Antigen/ml anti-adenosine.

$c$ Linked to Sepharose.

ing was diminished from $4.3 \mathrm{pmol} / \mathrm{ml}$ to an undetectable level $(<0.05 \mathrm{pmol} / \mathrm{ml})$ after elution through the column. Solid phase immunoabsorption, which removes the antibodies from the serum, also eliminated the immunocytochemical stain for adenosine (Table 1). Staining was abolished when serial vibratome sections were incubated with solid phase absorbed antiserum (data not shown).

Further evidence for the authenticity of the adenosine staining was obtained by enzymatic degradation of endogenous tissue adenosine prior to the immunocytochemical stain. Increasing pretreatment times of serial cryosections with adenosine deaminase, which catalyzes the conversion of adenosine to inosine, gradually reduced the stain intensity to background levels (Table 1). Staining was also absent when normal rabbit (preimmune) serum replaced the primary antibody. Additionally, staining was abolished when the primary antibody, secondary antibody, or either the $\mathrm{ABC}$ or PAP complex was omitted from the staining procedure (Table 1).

Endogenous adenosine levels vary depending upon the metabolic state of the tissue, increasing dramatically in hypoxia (Berne et al., 1974; Kleihues et al., 1974; Wojcik and Neff, 1982). Conceivably, adenosine may be homogeneously distributed in the brain, but increase to detectable levels only in metabolically active neurons. One would then expect the pattern of adenosinelike immunoreactivity in various brain regions to vary depend-
Table 2. Effect of fixation protocol on immunoreactive adenosine

\begin{tabular}{lll} 
& \multicolumn{2}{c}{ Relative stain intensity } \\
\cline { 2 - 3 } Protocol & Hippocampus & $\begin{array}{l}\text { Caudate- } \\
\text { putamen }\end{array}$ \\
\hline Prefixation saline perfusion time (min) & \\
0.0 & 3.5 & $1-1.5$ \\
0.5 & $3.5-4$ & $2-2.5$ \\
1.0 & 4 & 2.5 \\
5.0 & $4+$ & $2.5-3$ \\
Decapitation & $4+$ & 3 \\
Microwave irradiation & 3.5 & $1-1.5$
\end{tabular}

Adult male rats were intracardially perfused with saline for the indicated times prior to fixation with buffered $2.5 \%$ glutaraldehyde. Additional animals were either decapitated or microwave-irradiated and the tissues processed for cryostat sectioning. Tissue cryosections were stained using 1:7000 anti-adenosine, as described in Materials and Methods. Each experimental protocol was repeated 2-6 times, with similar results.

${ }^{a}$ Relative stain intensity: $\mathbf{4}=$ most intense; $0=$ no stain

ing upon the degree of tissue hypoxia. Accordingly, we conducted immunocytochemical stains for adenosine in brain tissue prepared by several methods. One group of animals was killed by microwave irradiation, which rapidly destroys enzymatic activities. The duration of the perfusion prewash prior to fixation with glutaraldehyde was varied in the second group of rats. A third group was killed by decapitation (Table 2).

The lowest intensities of adenosine-like immunoreactivity occurred in tissues from rats killed by microwave irradiation, while the highest immunoreactivities were found in tissue from animals killed by decapitation. Prolonging the duration of the perfusion prewash also increased staining intensities. However, regardless of the amount of endogenous immunoreactivities adenosine, the pattern of distribution of the immunoreactive throughout the cytoplasm of specific neuronal subpopulations in different regions of the brain showed no variation. The observed staining patterns, therefore, most likely reflected the localizations of endogenous adenosine in the intact animal.

\section{Immunocytochemical stain for adenosine: localization}

Adenosine-like immunoreactivity observed throughout rat brain was confined to neurons. Staining was most pronounced over neuronal cell bodies where immunoreactivity occurred throughout the cytoplasm, while staining was absent over nuclei (Fig. 1). Staining frequently extended into the dendritic and axonal processes of neurons. The most extensive staining of neuronal fibers and axon terminals was observed in brain stem and spinal cord.

Considerable regional variations in adenosine staining were detected (Figs. 2 and 3; Table 3). Strikingly discrete localization of adenosine-like immunoreactivity occurred in the hippocampal formation (Fig. 1, $A-D$ ). Intense stain was observed throughout the cell somas and fibers of the pyramidal cell layer (CA1CA4) of the hippocampus and the granule cell layer of the dentate gyrus.

A high density of immunoreactivity occurred in the primary olfactory cortex, where adenosine was localized in the discrete band of large neuronal cell somas. Other regions of the cerebral cortex also contained moderate to high immunoreactivity. Staining was most intense in deeper layers, especially in the perikarya and fibers of the pyramidal cells in layer $\mathrm{V}$, while no staining was observed in more superficial layers.

Moderately high levels of staining were observed in the thalamus, with variations among the thalamic subnuclei. Moderate to high adenosine immunoreactivity occurred throughout the 


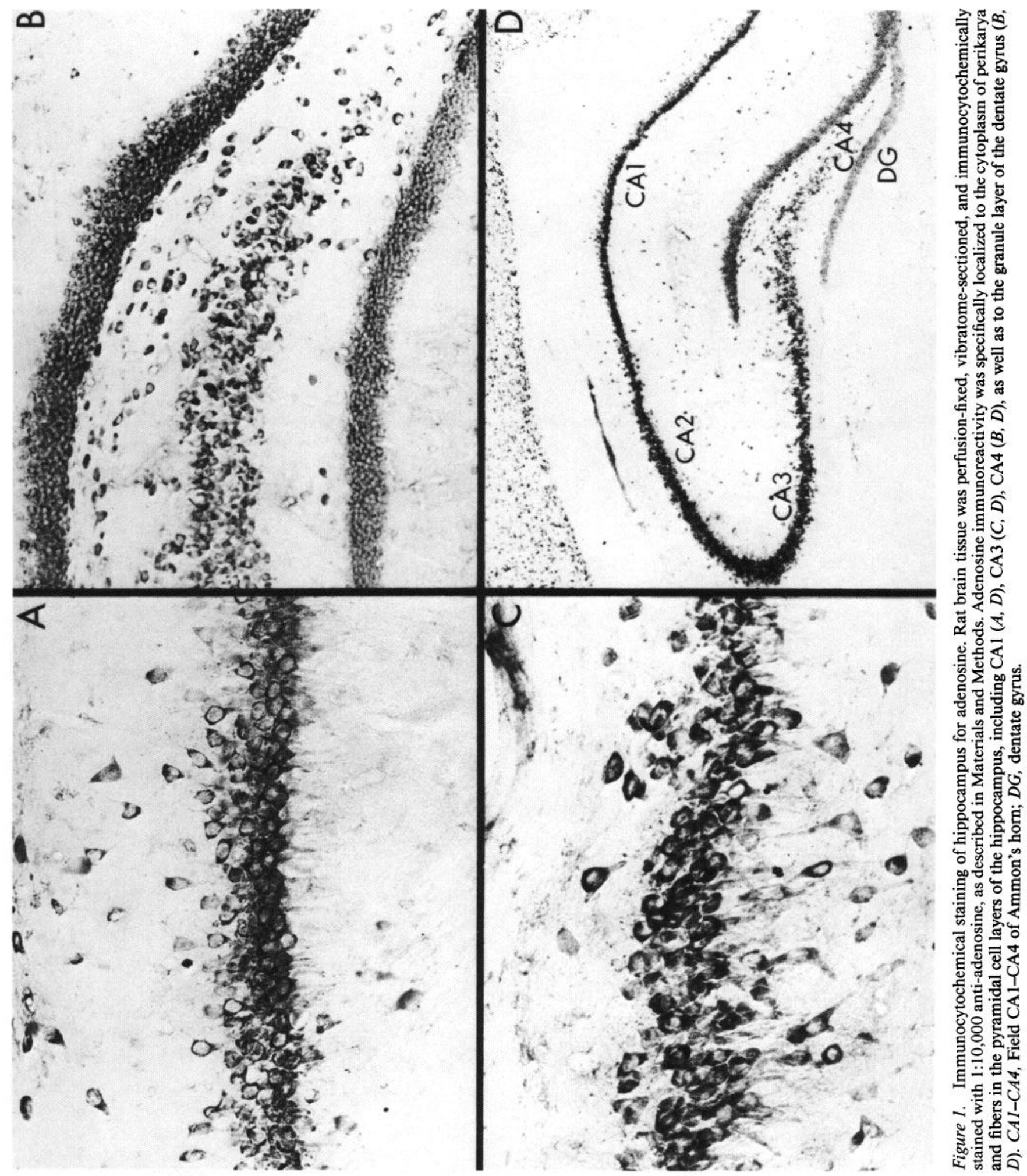




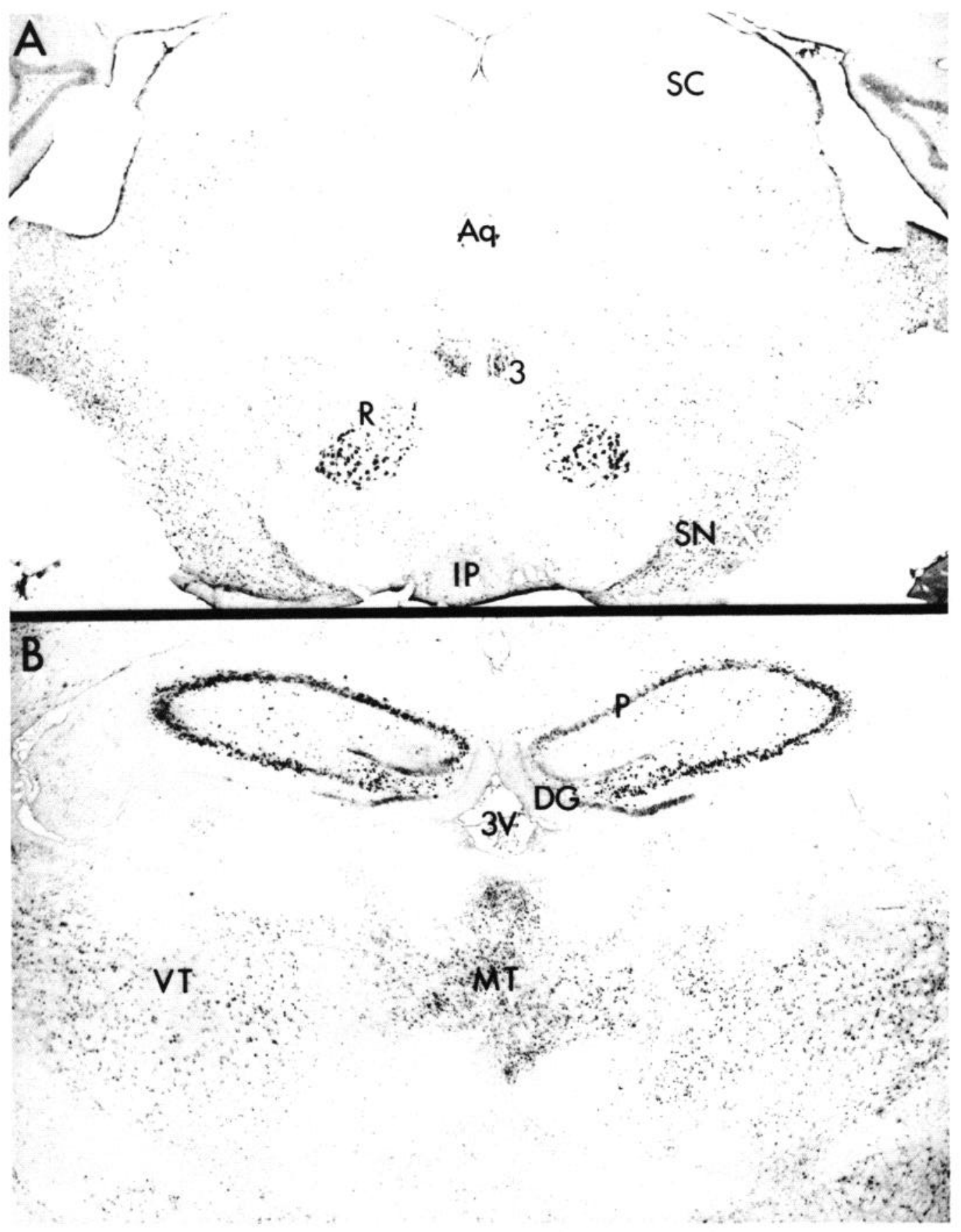

Figure 2. Staining of midbrain and forebrain regions for adenosine immunoreactivity. Vibratome tissue sections from the midbrain $(A)$ and forebrain $(B)$ were immunocytochemically stained using 1:7000 or 1:10,000 anti-adenosine. The red nucleus and oculomotor nucleus were prominently stained in the midbrain, with lesser staining in the substantia nigra, superior colliculus, and interpeduncular nuclei. In the forebrain, staining in the ventral and medial thalamus, as well as in the hippocampal formation, was prominent. Staining of the hippocampal formation is shown in greater detail in Figure 1. SC, Superior colliculus; 3, principal oculomotor nucleus; $R$, red nucleus (magnocellular); $S N$, substantia nigra; $I P$, interpeduncular nuclei; $A q$, cerebral aqueduct; $P$, pyramidal cell layer, hippocampus; $D G$, dentate gyrus; $M T$, medial thalamus; $V T$, ventral thalamus; $3 \mathrm{~V}$, third ventricle.

cytoplasm of cell bodies and extended into the fibers of neurons in the ventral and medial nuclei, while weaker to no stain was observed in the lateral and dorsal nuclei (Fig. $2 B$ ). The closely adjacent hypothalamus possessed substantially less adenosinelike immunoreactivity than the thalamus. Variations in staining were observed within the hypothalamus, with highest staining intensities in the lateral and mammillary areas.

Moderate staining was found in the corpus striatum and the amygdala. Staining in the caudate-putamen occurred in cell bodies along the superior and inferior borders, as well as in discrete patches within the body of the caudate-putamen. In the corpus striatum, the method of sacrifice strongly influenced the intensity of the staining (Table 2). Weak to no staining was observed in the globus pallidus. The amygdala possessed moderate immunoreactivity in cell bodies, with higher intensities in the basolateral nuclei and lesser intensities in the central nuclei. 


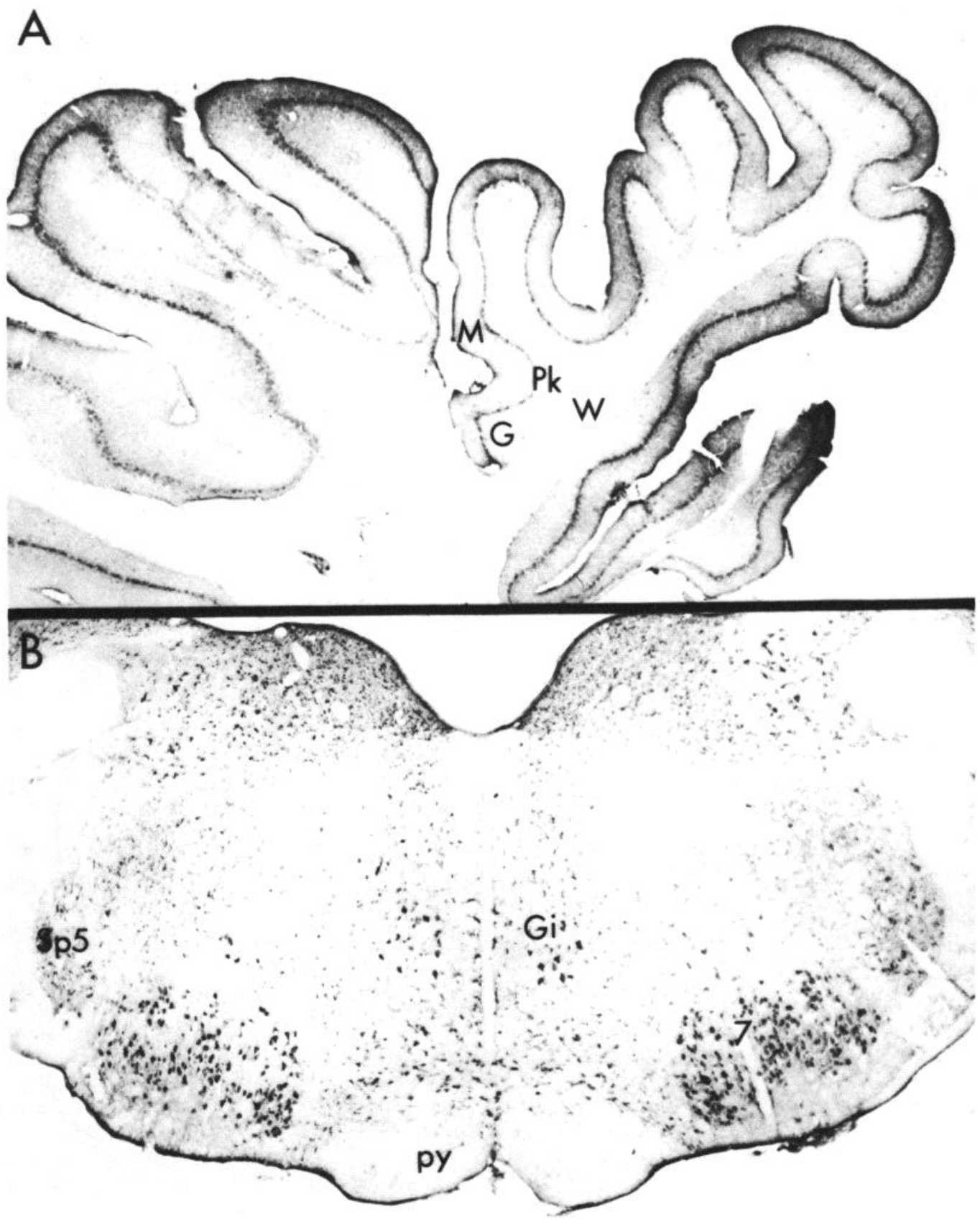

Figure 3. Immunocytochemical staining for adenosine in cerebellum and hindbrain. Vibratome sections through the cerebellum $(A)$ and hindbrain $(B)$ were processed for immunocytochemistry using 1:7000 or 1:10,000 anti-adenosine. The perikarya of the Purkinje cell layer of the cerebellum, as well as their dendrites extending into the molecular layer, were intensely stained. This is shown in greater detail in Figure $4 B$. No staining was observed in white matter. Adenosine immunoreactivity was found in neuronal cell bodies in discrete nuclei of the hindbrain, including the facial nucleus and gigantocellular reticular nucleus. $M$, Molecular layer; $P k$, Purkinje layer; $G$, granular layer; $W$, white matter; 7 , facial nucleus; $G i$, gigantocellular reticular nucleus; $S p 5$, nucleus spinal tract trigeminal nerve; $p y$, pyramidal tract; $4 V$, fourth ventricle.

In the brain stem, several patterns of localization occurred. Adenosine-like immunoreactivity was intensely concentrated in motor nuclei, including the red nucleus, the facial nucleus, the oculomotor nucleus, the motor nucleus of the trigeminal, and the hypoglossal nucleus (Figs. $2 A, 3 B, 4 C$ ). Moderate staining was apparent in sensory nuclei, such as the lateral vestibular nucleus (Fig. 4D) and the sensory nucleus of the trigeminal. The most prominent grouping of adenosine-containing fibers and terminals occurred in the spinal nucleus of the trigeminal nerve (Fig. 4A).
In the spinal cord, adenosine staining was similar to the patterns observed in the brain stem. The most intense immunoreactivity occurred in the motor nuclei in the ventral horn, while a band of staining was also apparent in fibers and terminals in the substantia gelatinosa.

Discrete localizations of adenosine immunoreactivity were also found in the cerebellum. Staining was highest in the Purkinje cells and in their dendrites extending into the molecular layer (Figs. $3 A, 4 B$ ). Weaker staining was observed in the granular layer, while staining was absent in the white matter. 


\begin{tabular}{|c|c|}
\hline Brain region & $\begin{array}{l}\text { Relative stain } \\
\text { intensity }^{a}\end{array}$ \\
\hline Primary olfactory cortex & $3.5-4$ \\
\hline \multicolumn{2}{|l|}{ Frontoparietal cortex } \\
\hline Lamina V, VI & $3-3.5$ \\
\hline Lamina IV & 1.5 \\
\hline Lamina II, III & 2.5 \\
\hline Lamina I & 0 \\
\hline Cingulate cortex & 3.5 \\
\hline Corpus callosum & 0 \\
\hline Fornix & 0 \\
\hline Anterior commissure & 0 \\
\hline Caudate-putamen & $2-3$ \\
\hline Globus pallidus & 0.5 \\
\hline Septal nuclei (medial and lateral) & 3 \\
\hline Accumbens nucleus & 2.5 \\
\hline \multicolumn{2}{|l|}{ Hippocampus } \\
\hline Pyramidal cell layer & 4 \\
\hline Granule cell layer of dentate gyrus & 3 \\
\hline \multicolumn{2}{|l|}{ Amygdala } \\
\hline Basolateral nucleus & 3 \\
\hline Central nucleus & 2 \\
\hline Medial nucleus & 1.5 \\
\hline Latcral nucleus & 2 \\
\hline \multicolumn{2}{|l|}{ Thalamus } \\
\hline Lateral & $1-2$ \\
\hline Ventral & 3.5 \\
\hline Medial & $2.5-3.5$ \\
\hline Anterior & $0.5-2.5$ \\
\hline \multicolumn{2}{|l|}{ Hypothalamus } \\
\hline Lateral & 3 \\
\hline Mammillary & 3 \\
\hline Superior colliculus & $2.5-3$ \\
\hline Central grey & 1.5 \\
\hline Principal oculomotor nucleus & 3 \\
\hline Red nucleus & 4 \\
\hline Interpeduncular nuclei & $2.5-3$ \\
\hline Substantia nigra & $2.5-3$ \\
\hline Motor trigeminal nucleus & 4 \\
\hline Pontine reticular nucleus & $3.5-4$ \\
\hline Parvocellular reticular nucleus & $3.5-4$ \\
\hline Gigantocellular reticular nucleus & 3.5 \\
\hline Nucleus mesencephalic tract trigeminal nerve & 3 \\
\hline
\end{tabular}

\section{Discussion}

The present study demonstrates the localization of adenosinelike immunoreactivity in select neurons within the rat brain. Extensive biochemical and immunocytochemical control studies have established that the staining likely involves chemically authentic adenosine. Since the immunocytochemical staining patterns werc unaltered by the duration of hypoxia prior to tissue-processing, the observed localizations most probably reflect the endogenous disposition of adenosine in intact animals.

Examination of adenosine-like immunoreactivity throughout the CNS of the rat has failed to demonstrate staining in any structures other than neurons. The heterogeneous distribution of these neurons throughout the CNS resembles the disposition of neuronal pathways for most neurotransmitters (Bjorklund and Hokfelt, 1983, 1984; Bjorklund et al., 1984; Krieger et al., 1983). Interestingly, staining of neurotransmitters, especially
Table 3. Continued

\begin{tabular}{ll} 
Brain region & $\begin{array}{l}\text { Relative stain } \\
\text { intensity }^{a}\end{array}$ \\
\hline Trapezoid body, medial and lateral & $3-3.5$ \\
Facial nucleus & 4 \\
Principal sensory trigeminal nucleus & 3 \\
Nucleus spinal tract trigeminal nerve & 3 \\
Vestibular nuclei & $2.5-3.5$ \\
Hypoglossal nucleus & 3.5 \\
Inferior olive & $2.5-3$ \\
Cerebellum & \\
Molecular layer & 2.5 \\
Purkinje layer & 3.5 \\
Granule layer & $1.5-2$ \\
White matter & 0 \\
Spinal cord & \\
Substantia gelatinosa & \\
Motor nuclei & $2.5-3$ \\
\hline
\end{tabular}

Adult male rats were intracardially perfused for $0.5 \mathrm{~min}$ with prewash prior to fixation with buffered $2.5 \%$ glutaraldehyde. Vibratome or cryostat tissue sections were immunocytochemically stained using 1:7000-1:12,000 anti-adenosine, as described in Materials and Methods. Relative stain intensity in brain sections taken at $500 \mu \mathrm{m}$ intervals was evaluated according to coronal levels in the atlas of Paxinos and Watson (1982). Experiments were repeated 10 times, with similar results.

${ }^{a}$ Relative stain intensity: $4=$ most intense; $0=$ no stain.

neuropeptides, often detects fiber systems but reveals cell bodies only upon blockade of axoplasmic transport. In contrast, adenosine is primarily localized to perikarya, while dense plexi of fibers are most apparent in the brain stem and spinal cord.

A variety of biochemical markers that may be related to adenosine has been localized at a microscopic level in specific regions of the brain. These studies have included localizations of adenosine receptors, adenosine uptake sites, and the enzymes involved in adenosine metabolism. Adenosine deaminase, which catalyzes the conversion of adenosine to inosine, has been localized by immunocytochemistry (Nagy et al., 1984a, b, 1985). Adenosine uptake sites have been localized by autoradiography with the uptake inhibitor ${ }^{3} \mathrm{H}$-nitrobenzylthioinosine, while adenosine $\mathrm{A}_{2}$ receptors have been localized with ${ }^{3} \mathrm{H}$-cyclohexyladenosine (Bisserbe et al., 1985; Goodman and Snyder, 1981, 1982; Lewis et al., 1981; Nagy et al., 1985). 5'-Nucleotidase, an enzyme involved in the dephosphorylation of adenosine monophosphate to adenosine, has also been localized (Marani, 1977; Scott, 1964, 1967).

Adenosine deaminase has a very restricted localization. High levels of adenosine deaminase immunoreactivity appear predominantly in the tuberal, caudal, and postmammillarycaudal magnocellular neuronal cell bodies and fibers of the basal hypothalamus (Nagy et al., 1984a). Although this distribution differs from the much more widespread occurrence of adenosinelike immunoreactivity, the most intense staining of endogenous adenosine within the hypothalamus also occurs in perikarya and fibers of this region. Adenosine deaminase immunoreactivity has also been detected in cell bodies of small type B neurons in the dorsal root ganglion and in neurons in the superior colliculus (Nagy et al., 1984b, 1985). Although the dorsal root ganglion was not examined for endogenous adenosine immunoreactivity, moderate levels of staining were observed in axons and terminals in the substantia gelatinosa, where sensory neurons terminate.

While there are similarities among the localizations of the various biochemical markers, some marked differences also exist. For instance, although immunoreactive adenosine, adeno- 


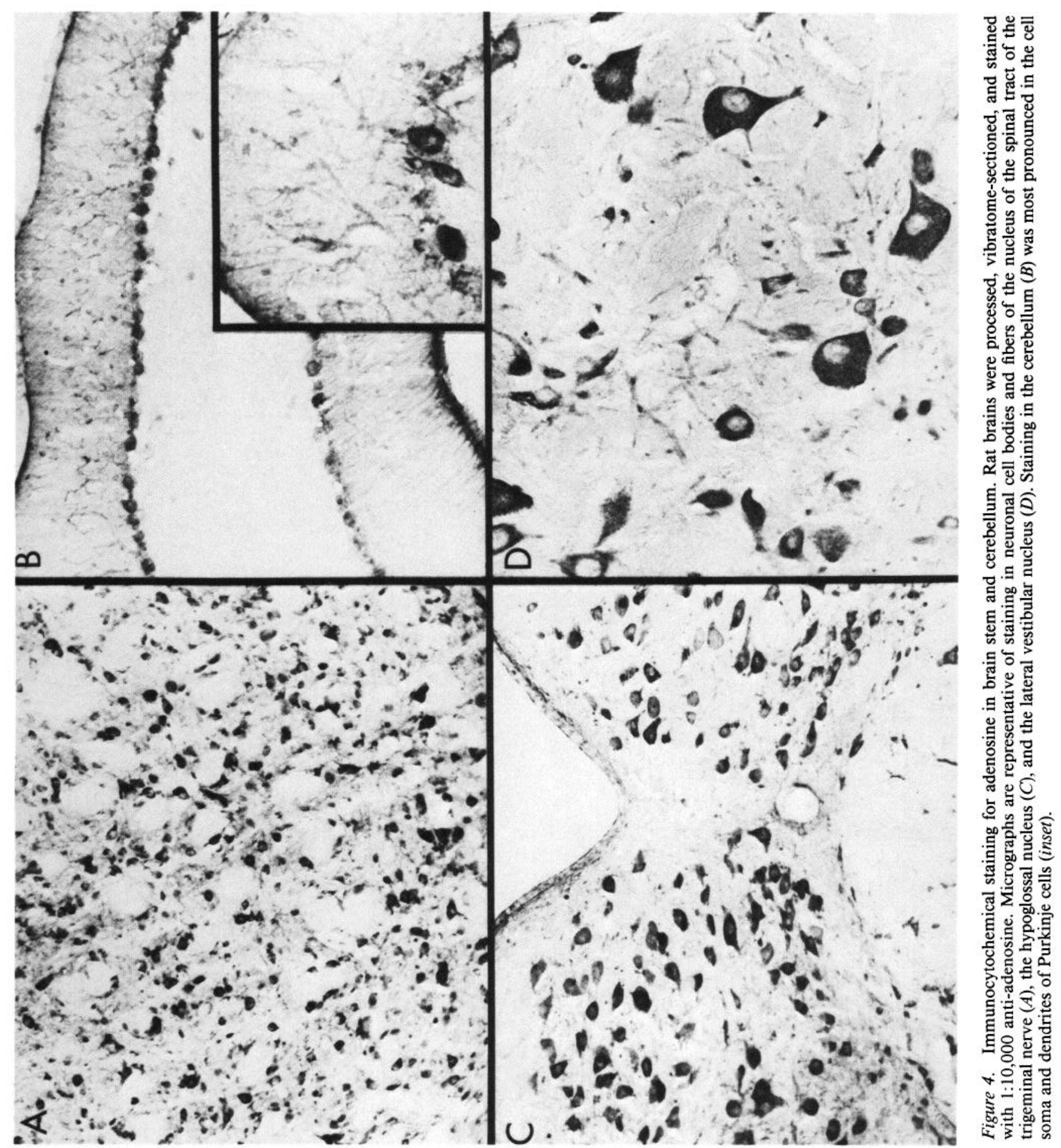


sine uptake sites, $A_{1}$ receptors, and 5 '-nucleotidase all occur in the thalamus, their relative levels differ in various thalamic subnuclei (Goodman and Snyder, 1982; Phillis and Wu, 1981; Scott, 1967). In the amygdala, immunoreactive adenosine is highest in the basolateral nucleus, which possesses the lowest levels of adenosine uptake sites and $A_{1}$ receptors. The central nucleus of the amygdala has the highest levels of $A_{1}$ receptor, but the lower levels of both adenosine immunoreactivity and uplake sites (Bisserbe et al., 1985; Goodman and Snyder, 1982). The hippocampus possesses high levels of 5 -nucleotidase, $\mathrm{A}_{1}$ receptors, and adenosine immunoreactivity, but relatively low levels of adenosine uptake sites (Bisserbe et al., 1985; Goodman and Snyder, 1982; Scott, 1967). In the cerebellum, high levels of 5'-nucleotidase (Scott, 1964, 1967) and $A_{1}$ receptors (Goodman and Snyder, 1982; Goodman et al., 1983) are localized in the molecular layer; lower levels exist in the granule cell layer. Cerebellar 5'-nucleotidase is associated with Purkinje cell dendrites, parallel fibers, and synapses between parallel fibers and Purkinje cell spines (Marani, 1977). $A_{1}$ receptors appear to be located on axon terminals of excitatory granule cells (Goodman et al., 1983; Wojcik and Neff, 1983). In this instance, the results correspond fairly well to the localization of endogenous adenosine to Purkinje cells and their processes, which extend into the molecular layer of the cerebellum.

The marked differences in localization of various markers pose difficulties in formulating models of adenosine functions. There are many possible explanations for these discrepancies. Adenosine uptake sites and adenosine deaminase may be associated with metabolic stores of adenosine unrelated to neurotransmitter or neuromodulatory pools of adenosine. The observed staining patterns may reflect the distribution of neurons with high metabolic activity and hence relatively high levels of endogenous adenosine, rather than distribution of neuronal cells in which adenosine serves as a neurotransmitter. 5 -Nucleotidase may serve other metabolic functions aside from adenosine biosynthesis. Indeed, whether endogenous adenosine arises via this enzyme or through other pathways, such as $S$-adenosylhomocysteine hydrolase, has not been established. Most of the adenosine immunoreactivity described here is localized to neuronal cell somas. Receptor sites, on the other hand, would be expected to be in close proximity to adenosine nerve terminals that might be distant from the cell bodies. Similarly, adenosine uptake sites would be expected to be most concentrated in terminals. Finally, the localization of $A_{2}$ receptors has not been established. Whether most of the endogenous adenosine in the brain interacts with $A_{1}$ or $A_{2}$ receptors also remains unclear.

\section{References}

Barraco, R. A., V. I. Coffin, H. J. Altman, and J. W. Phillis (1983) Central effects of adenosine analogs and locomotor activity in mice and antagonism of caffeine. Brain Res. 272: 392-395.

Bender, A. S., P. H. Wu, and J. W. Phillis (1980) The characterization of $\left[{ }^{3} \mathrm{H}\right]$-adenosine uptake into rat cerebral cortical synaptosomes. $\mathbf{J}$. Neurochem. 35: 629-640.

Bender, A. S., P. H. Wu, and J. W. Phillis (1981) The rapid uptake and release of $\left[{ }^{3} \mathrm{H}\right]$-adenosine by rat cerebral cortical synaptosomes. J. Neurochem. 36: 651-660.

Berne, K. M., R. Kubio, and R. K. Curnish (1974) Release of adenosine from ischemic brain. Effect of cerebral vascular resistance and incorporation into cerebral adenine nucleotides. Circ. Res. 35: 262-271.

Bisserbe, J. C., J. Patel, and P. J. Marangos (1985) Autoradiographic localization of adenosine uptake sites in rat brain using $\left[{ }^{3} \mathrm{H}\right]$-nitrobenzylthioinosine. J. Neurosci. 5: 544-550.

Bjorklund, A., and T. Hokfelt, eds. (1983) Methods in Chemical Neuroanatomy, Elsevier, New York.

Bjorklund, A., and T. Hokfelt, eds. (1984) Classical Transmitters in the CNS, Pt. I, Elsevier, New York.

Bjorklund, A., T. Hokfelt, and M. J. Kuhar, eds. (1984) Classical Trunsmitter Receptors in the CNS, Pt. II, Elsevier, New York.

Braas, K. M., S. R. Childers, and D. C. U'Prichard (1983) Induction of differentiation increases $\mathrm{Met}^{5}$-enkephalin and $\mathrm{Leu}^{5}$-enkephalin content in NG108-15 hybrid cells: An immunocytochemical and biochemical analysis. J. Neurosci. 3: 1713-1727.

Braas, K. M., A. C. Newby, and S. H. Snyder (1985) Adenosine containing neurons localized by immunocytochemistry. In Proceedings of the International Workshop on Adenosine and Xanthine Derivatives, V. Stefanovich, K. Rudolphi, and P. Schubert, eds., pp. 59-90, IRL, Oxford, UK.

Childs, G., and G. Unabia (1982) Application of the avidin-biotinperoxidase complex $(\mathrm{ABC})$ method to the light microscopic localization of pituitary hormones. J. Histochem. Cytochem. 30: 713-716.

Cooper, D. M. F., C. Londos, and M. Rodbell (1980) Adenosine receptor-mediated inhibition of rat cerebral cortical adenylate cyclase by a GTP-dependent process. Mol. Pharmacol. 19: 598-601.

Dunwiddie, T. V., and B. B. Fredholm (1984) Adenosine receptors mediating inhibitory electrophysiological responses in rat hippocampus are different from receptors mediating cyclic AMP accumulation. Naunyn-Schmiedebergs Arch. Pharmacol. 326: 294-301.

Fredholm, B. B., and P. Hedqvist (1980) Modulation of neurotransmission by purine nucleotides and nucleosides. Biochem. Pharmacol. 29: $1635-1643$.

Gendelman, H. E., T. R. Moench, O. Narayan, and D. E. Griffin (1983) Selection of a fixative for identifying $T$ cell subsets, B cells, and macrophages in paraffin-embedded mouse spleen. J. Immunol. Methods 65: $137-145$.

Goodman, R. R., and S. H. Snyder (1981) The light microscopic in vitro autoradiographic localization of adenosine receptors. Neurosci. Abstr. 7: 613.

Goodman, R. R., and S. H. Snyder (1982) Autoradiographic localization of adenosine receptors in rat brain using $\left[{ }^{3} \mathrm{H}\right]$-cyclohexyladenosine. J. Neurosci. 2: 1230-1241.

Goodman, R. R., M. J. Kuhar, L. Hester, and S. H. Snyder (1983) Adenosine receptors: Autoradiographic evidence for their location on axon terminals of excitatory neurons. Science 220: 967-969.

Harms, H. H., G. Wardeh, and A. H. Mulder (1979) Effects of adenosine on depolarization-induced relcasc of various radiolabeled neurotransmitters from slices of rat corpus striatum. Neuropharmacology 18: $557-580$.

Hsu, S.-M., L. Raine, and H. Fanger (1981) Use of avidin-biotinperoxidase complex $(A B C)$ in immunoperoxidase techniques. J. Histochem. Cytochem. 29: 577-580.

Jacobowitz, D. M. (1974) Removal of discrete fresh regions of rat brain. Brain Res. 80: 111-115.

Jarvis, S. M., and J. D. Young (1980) Nucleoside transport in human and sheep erythrocytes: Evidence that nitrobenzylthioinosine binds specifically to functional nucleoside transport sites. Biochem. J. 190 $377-383$.

Katims, J. J., Z. Annau, and S. H. Snyder (1983) Interactions in the behavioral effects of methylxanthines and adenosine derivatives. $J$. Pharmacol. Exp. Ther. 227: 167-173.

Kleihues, P., K. Kobayashi, and K.-A. Hossmann (1974) Purine nucleotide metabolism in the cat brain after one hour of complete ischemia. J. Neurochem. 23: 417-425.

Kocsis, J. D., D. L. Eng, and R. B. Bhisitkul (1984) Adenosine selectively blocks parallel-fiber-mediated synaptic potentials in rat cerebellar cortex. Proc. Natl. Acad. Sci. USA 81: 6531-6534.

Kostopoulos, G. K., and J. W. Phillis (1977) Purinergic depression of neurons in different areas of the rat brain. Exp. Neurol. 55: 719-724.

Kostopoulos, G. K., J. J. Limacher, and J. W. Phillis (1975) Action of various adenine derivatives on cerebellar Purkinje cells. Brain Res. 88: 162-165.

Krieger, D. T., M. J. Brownstein, and J. B. Martin, eds. (1983) Brain Peptides, Wiley, New York.

Kuroda, Y., and $\mathrm{H}$. Mcllwain (1974) Uptake and release of $\left[{ }^{14} \mathrm{C}\right]-$ adenine derivatives at beds of mammalian cortical synaptosomes in a superfusion system. J. Neurochem. 22: 691-699.

Lewis, M. E., J. Patel, S. Moon Edley, and P. J. Marangos (1981) Autoradiographic visualization of rat brain adenosine receptors using N-6-cyclohexyl [ $\left.{ }^{3} \mathrm{H}\right]$-adenosine. Eur. J. Pharmacol. 73: 109-110.

Marangos, P. J., J. Patel, R. Clark-Rosenberg, and A. M. Martino (1982) $\left[{ }^{3} \mathrm{H}\right]-$ Nitrobenzylthioinosine binding as a probe for the study of adenosine uptake sites in the brain. J. Neurochem. 39: 184-191.

Marani, E. (1977) The subcellular distribution of 5'-nucleotidase activity in mouse cerebellum. Exp. Neurol. 57: 1042-1048.

McLean, I. W., and P. K. Nakane (1974) Periodate-lysine-paraformaldehyde fixative, a new fixative for immunoelectron microscopy. J. Histochem. Cytochem. 22: 1077-1083. 
Moriarty, G. C., and N. S. Halmi (1972) Electron microscopic study of the adrenocorticotropin-producing cell with unlabeled antibody and the peroxidase anti-peroxidase complex. J. Histochem. Cytochem. 20: 590-603.

Nagy, J. I., L. A. LaBella, M. Buss, and P. E. Daddona (1984a) Immunohistochemistry of adenosine deaminase: Implications for adenosine neurotransmission. Science 224: 166-168.

Nagy, J. I., M. Buss, L. A. LaBella, and P. E. Daddona (1984b) Immunohistochemical localization of adenosine deaminase in primary afferent neurons of the rat. Neurosci. Lett. 48: 133-138.

Nagy, J. I., J. D. Geiger, and P. E. Daddona (1985) Adenosine uptake sites in rat brain: Identification using $\left[{ }^{3} \mathrm{H}\right]$-nitrobenzylthioinosine and co-localization with adenosine deaminase. Ncurosci. Lett. 55: 47-53.

Newby, A. C., and G. B. Sala (1982) A new procedure for haptenizing adenosine leading to a more specific radioimmunoassay method. Biochem. J. 208: 603-610.

Paxinos, G., and C. Watson (1982) The Rat Brain in Stereotaxic Coordinates, Academic, New York.

Phillis, J. W., and P. H. Wu (1981) The role of adenosine and its nucleotides in central synaptic transmission. Prog. Neurobiol. 16: 187-239.

Phillis, J. W., J. P. Edstrom, G. K. Kostopoulos, and J. R. Kirkpatrick (1979) Effects of adenosine and adenine nucleotides on synaptic transmission in the cerebral cortex. Can. J. Physiol. Pharmacol. 57: 1289-1312.

Pull, I., and H. Mcllwain (1977) Adenine mononucleotides and their metabolites liberated from and applied to isolated tissues of the mammalian brain. Neurochem. Res. 2: 203-216.

Scott, T. G. (1964) A unique pattern of localization within the cerebellum of the mouse. J. Comp. Neurol. 122: 1-7.

Scott, T. G. (1967) The distribution of 5'-nucleotidase in the brain of the mouse. J. Comp. Neurol. 129: 97-113.
Seela, F., and F. Cramer (1975) Synthese eines bis-adenosin-derivates als analogon zum Ubergangszustand der tRNA-abhangigen peptidkondensation. Chem. Ber. 108: 1329-1338.

Seela, F., and S. Waldek (1975) Agarose linked adenosine and guanosine-5'-monophosphate; a new general method for the coupling of ribonucleotides to polymers through their cis-diols. Nucleic Acids Res. 2: 2343-2354.

Shimizu, H., S. Tanaka, and T. Kodoma (1972) Adenosine kinase of mammalian brain: Partial purification and its role for the uptake of adenosine. J. Neurochem. 19: 687-698.

Snyder, S. H., J. J. Katims, Z. Annau, R. F. Bruns, and J. W. Daly (1981) Adenosine receptors and behavioral actions of methylxanthincs. Proc. Natl. Acad. Sci. USA 78: 3260-3264.

Sternberger, L. A., P. H. Hardy, J. J. Cuculis, and H. G. Meyer (1970) The unlabeled antibody enzyme method of immunocytochemistry: Preparation and properties of soluble antigen-antibody complexes (horseradish peroxidase-antiperoxidase) and its use in identification of spirochetes. J. Histochem. Cytochem. 18: 315-333.

Stone, T. W. (1981) Physiological roles for adenosine and adenosine 5 triphosphate in the nervous system. Neuroscience 6: 523-555.

Van Calker, D., M. Muller, and B. Hamprecht (1979) Adenosine regulates via two different types of receptors: The accumulation of cyclic AMP in cultured brain cells. J. Neurochem. 33: 999-1005.

Winn, H. R., J. E. Welsh, R. Rubio, and R. M. Berne (1980) Changes in brain adenosine during bicuculline-induced seizures in rats. Effects of hypoxia and altered systemic blood pressure. Circ. Res. 47: 568577.

Wojcik, W. J., and N. H. Neff (1982) Adenosine measurement by a rapid HPLC-fluorometric method: Induced changes of adenosine content in regions of rat brain. J. Neurochem. 39: 280-282.

Wojcik, W. J., and N. H. Neff (1983) Adenosine $A_{1}$ receptors are associated with cerebellar granule cells. J. Neurochem. 41: 759-763. 